\title{
RADIONUCLIDES IN ORTHOPAEDIC SURGERY
}

\author{
SEAN HUGHES \\ From the University Department of Orthopaedic Surgery, \\ Princess Margaret Rose Orthopaedic Hospital, Edinburgh
}

Bone scanning with radioactive isotopes has become a routine method for investigating disorders of bone. Departments of nuclear medicine throughout the country offer diagnostic facilities for a variety of problems which affect not only bone, but also the heart, kidney, brain, liver, pancreas and spleen as well as disorders of the blood. Indeed the use of radionuclides is now an important and established part of investigative medicine. It is the purpose of this article to present the role of radionuclides in orthopaedic diagnosis. For a long time the essential confirmatory diagnostic method in orthopaedic practice has been the use of radiographs which demonstrate clearly the pathology in the bone but in two dimensions. What troubles many orthopaedic surgeons is the ability to note the state of the bone and not to be able to detect the period the bone has been affected. In other words, is the increased density noted in the radiographs of the hip in Perthes' disease the end of the disease when the bone has healed and revascularised, or is it a stage when the bone is actually being destroyed?

To help clarify the situation bone scanning with radionuclides has been introduced. By looking at bone in a three-dimensional way, whole new fields of bone turnover and mineral distribution have been explored. It is now possible to look at bone and study what is actually happening at the moment of the bone scan. However, in order to interpret the scan it is vital to understand the mechanism of bone scanning.

\section{ISOTOPES}

Until recently the radioactive isotopes that were available were strontium- 85 and strontium $-87 \mathrm{~m}$, which are known to exchange directly with calcium in the hydroxyapatite crystal of bone. However, the count rate from these isotopes is rather low and therefore skeletal detail is not well shown. Strontium-85 has a long half-life of 65 days and although strontium $-87 \mathrm{~m}$ has a half-life of only 2 hours 40 minutes it takes over 30 hours to be cleared from the blood. Fluorine-18 is an isotope that was introduced not long ago and it has a very short half-life of 110 minutes. It is a high-energy gamma emitter, but is usually only produced by a cyclotron and therefore has a limited distribution and availability.
In 1971 phosphate compounds were introduced as bone-scanning agents by Subramanian et al. The phosphate compounds are long-chain polymers of phosphates which have been used for years in the chemical industries. It is believed that the phosphate compounds bind directly with the hydroxyapatite crystal of the bone (Jung, Bisaz and Fleisch 1973). Subramanian labelled polyphosphate, one of the short-chain phosphate compounds, with technetium- $99 \mathrm{~m}$ which is a readily available isotope with a short half-life of six hours and has an energy of 140 kilo-electronvolts which is ideal for scanning because it produces a very low dose (0.05 rads per millicurie) to the skeleton. There are several phosphate compounds available, including pyrophosphate, tripolyphosphate and diphosphonates. The diphosphonates are phosphate-carbon-phosphate compounds and are rapidly cleared from the blood giving a high ratio of bone to soft tissue at four hours, which is the time of bone scanning (Yano et al. 1973). Of the phosphate compounds available the diphosphonates appear to be the best both experimentally (Hughes, Jeyasingh and Lavender 1975) and in clinical practice (Citrin et al. 1974).

\section{TECHNIQUE}

There are two main methods of detecting isotopes in bone, one by the use of the whole-body rectilinear scanner and the other by large-field gamma cameras, attached to scanning beds. By using these instruments the entire skeleton can be viewed easily in 45 minutes. Anteroposterior views of the skeleton are preferred and are almost always sufficient to provide the answers to a clinical problem. The images are generally reduced by a ratio of $5: 1$, but regions of interest can be reproduced life-size. The resolution of the modern imaging devices has progressively improved and considerable detail can now be recognised in the skeletal images. The individual vertebrae can be clearly seen and the ribs outlined well. However, in some patients, mainly obese ones, even the best radiopharmaceutical product cannot produce the required amount of detail.

It is necessary to appreciate that the size of the lesion alone is not the only factor visible on the bone scan. The metabolic activity of the bone is of great 
importance and therefore sometimes small but very active lesions are seen more clearly on the scan than much larger ones.

In order to be able to apply these techniques to clinical practice, it is obviously important to have an understanding of the mechanism of uptake of isotopes in bone.

\section{MECHANISM OF MINERAL UPTAKE IN BONE}

Bone. Bone is an active structure comprising both organic and inorganic components. The organic component is 35 per cent of the weight and consists of cells, collagen, mucopolysaccharides and the tissue fluid. The inorganic component is in the form of hydroxyapatite crystals and accounts for 65 per cent of the weight (Glimcher, Andrikides and Kossiva 1965). The length of the hydroxyapatite crystals in bone varies between 30 and 50 nanometres with a width of 15 nanometres and a thickness of 10 nanometres (Robinson 1952). To reach the hydroxyapatite crystal solutes must leave the capillaries which lie within the cortical bone.

Blood supply of bone. The blood supply of tubular bone is derived from the nutrient artery with its metaphysial and periosteal vessels. The nutrient artery traverses the nutrient canal without giving off collaterals to the cortex. From the medulla the vessels turn to the cortex in a longitudinal direction within the haversian system (Brooks and Harrison 1957). The terminal branches of the nutrient artery freely communicate with the blood vessels in the haversian canal (Clark 1945). The haversian systems anastomose with one another; they consist of irregular cylindrical structures comprising concentric lamellae of both bone substances and osteocytes arranged in rings round the central canal. The haversian system therefore consists of capillaries, bone cells and the hydroxyapatite. Cohen and Harris (1958) reported that the haversian canal increases in size within the bone itself, the larger vessels being near to the endosteum and the smaller vessels near to the periosteum. The size of the capillaries in the bone marrow has been estimated to be 80 nanometres in diameter (Brånemark 1961). Blood flows from the medulla to the cortex (Brookes et al. 1961). Lopez-Curto, Bassingthwaighte and Kelly (1977) have demonstrated by the technique of injecting Microphil into the canine tibia that the arterioles that supply the cortex do not supply the marrow sinusoids but drain into the venous network of the periosteum. They concluded that the circulations of the cortex and the marrow are mainly in parallel rather than in series with each other.

Capillaries. Capillaries are tubes which consist of walls composed of a single layer of endothelial cells. This thin wall is appropriate for transmural exchange and allows both solutes and solvents to pass readily backwards and forth by the process of diffusion. Majno (1965) has shown that in general there are three types of capillaries: continuous, fenestrated and discontinuous. In muscle, lung, central nervous tissue, adipose tissue and connective tissue the size of the capillaries has been estimated to be 100 nanometres in diameter with the cell junctions four nanometres in diameter (Karnovsky 1968). We have found similar capillaries in cortical bone.

Transcapillary exchange. Transcapillary exchange occurs principally by the method of diffusion. Pappenheimer (1953) showed that the passage of water and lipid in soluble molecules takes place by passive diffusion through pores in the capillary walls. He estimated these pores to have a radius of between three and four nanometres and suggested that diffusion rather than filtration was the mechanism by which small molecules could rapidly exchange between the blood and the interstitial fluid. The passage of a solute through a membrane is governed by the first law of Fick (1855) which stated that the flux of a substance is proportional to the diffusion coefficient, the area and the concentration gradient across which the substance passed. Hence, the larger the molecule, and therefore the larger the diffusion coefficient, the slower the diffusion and the slower the flux.

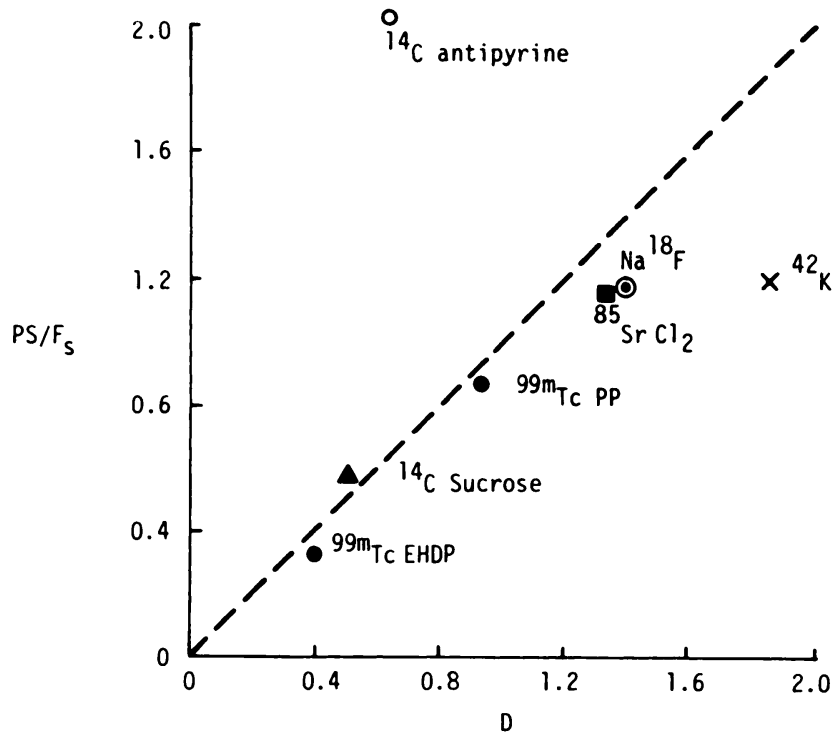

Fig. 1

The linear relationship between diffusion coefficients $(D)$ and the product of permeability and surface area divided by flow for the lipid-insoluble substances.

The transcapillary exchange of minerals in bone in the dog has been examined by using outflow dilution techniques (Davies, Bassingthwaighte and Kelly 1976; Hughes, Davies, Bassingthwaighte, Knox and Kelly 1977). It has been possible to measure the instantaneous extraction of substances such as strontium, sucrose, fluorine, diphosphonate and pyrophosphate and the maximal instantaneous extraction has been stated to be the best indication of extraction before any recirculation occurs (Bassingthwaighte 1974). Using the outflow dilution techniques and combining a reference tracer 
with a test tracer, and assuming that both of these tracers are equally dispersed in the blood stream and that reflux is negligible, the fractional extraction $(E)$ can be used to calculate the product of permeability and surface area (Renkin 1959; Crone 1963b). $P S=-F_{\mathrm{s}} \log _{\mathrm{e}}(1-E)$ where $P$ is the permeability of the capillaries in centimetres per second, $S$ is the capillary surface area in square centimetres per gram and $F_{\mathrm{s}}$ is the flow of the plasma in millilitres per gram per minute. However, this relationship is dependent upon there being a large enough fluid space in the tissue under study to minimise early return of the tracer from the tissue fluid to the blood.

Crone (1963a) showed that if two test tracers and an intravascular tracer were injected simultaneously into an artery supplying muscle, a ratio of permeabilities could be derived; from this he was able to calculate the permeability ratio of inulin to sucrose in muscle. He found that the permeability ratio was approximately proportional to the ratio of the free diffusion coefficients. He postulated, therefore, that for these molecules there is probably no restriction to free diffusion through the capillary clefts and that it was possible to relate the diffusion coefficient ratio of substances, based upon their molecular weight, to the permeability ratio based upon measured extraction. This technique has been applied to bone and the results are expressed in Figure 1. There is a clear linear relationship between the permeability ratio and diffusion coefficients for diphosphonate, sucrose, pyrophosphate, strontium, fluorine and potassium. Antipyrine has no relationship, as it is a fat-soluble substance and therefore does not pass through the transcapillary clefts.

Hence it is possible to establish that diffusion in bone through the capillaries occurs by passive free diffusion dependent solely upon molecular size, as the smaller molecules have a higher extraction than the larger molecules. The effect of ionic charge on the rate of transcapillary permeation has also been examined and has been found not to have any effect.

Fluid space. For the principles outlined above to be truly applicable to bone, it is essential that there is a fluid space across which diffusion can occur. Fluid occupies the region between the cell lining, the bone surfaces and the calcified tissue. It surrounds the osteoid and fills the space between the capillary wall and the bone cells. These spaces have been shown to be present by electron microscopy (Cooper, Milgram and Robinson 1966) and by measurement of albumin concentration (Owen, Triffitt and Melick 1973). Using a triple-isotope technique, fluid space in the canine tibia has also been measured (Lopez-Curto et al. 1976). Wash-out curves have been constructed to study fluid spaces (Hughes, Davies, Khan and Kelly 1978) and a typical wash-out curve for diphosphonate is shown in Figure 2. The curve can be stripped into three components, one has a half-life of three minutes, one has a half-life of $\mathbf{1 7 . 5}$

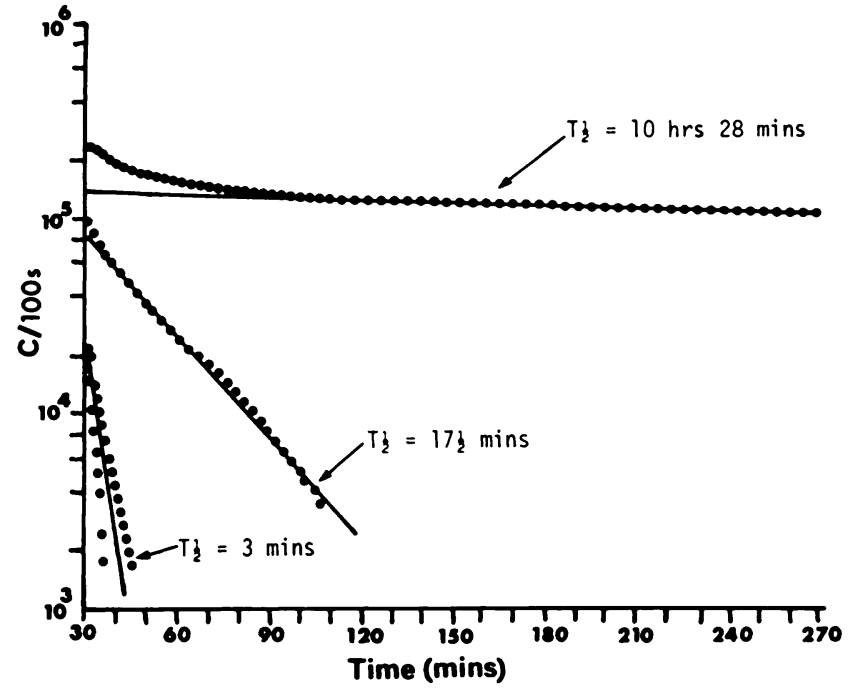

Fig. 2

A wash-out curve after an infusion of ${ }^{49 m} \mathrm{Tc}-\mathrm{MDP}$, showing the curve stripped into three components.

minutes and one has a half-life of 10 hours 28 minutes. Injection of red blood cells into the same model produced a very rapid single component with a half-life of 20 seconds. After a bolus of ${ }^{99 m}$ Tc-MDP there are four definable components to each curve. Component 1 has a half-life $35 \pm 7$ seconds; Component 2 a half-life of $3.6 \pm 0.4$ minutes; Component 3 a half-life of $15.6 \pm 1.6$ minutes; and Component 4 a half-life of $14.4 \pm 2.8$ hours (mean \pm SEM, $n=5$ ). It is therefore possible to suggest that the typical haversian system consists of four clear compartments: the capillaries, the perivascular fluid

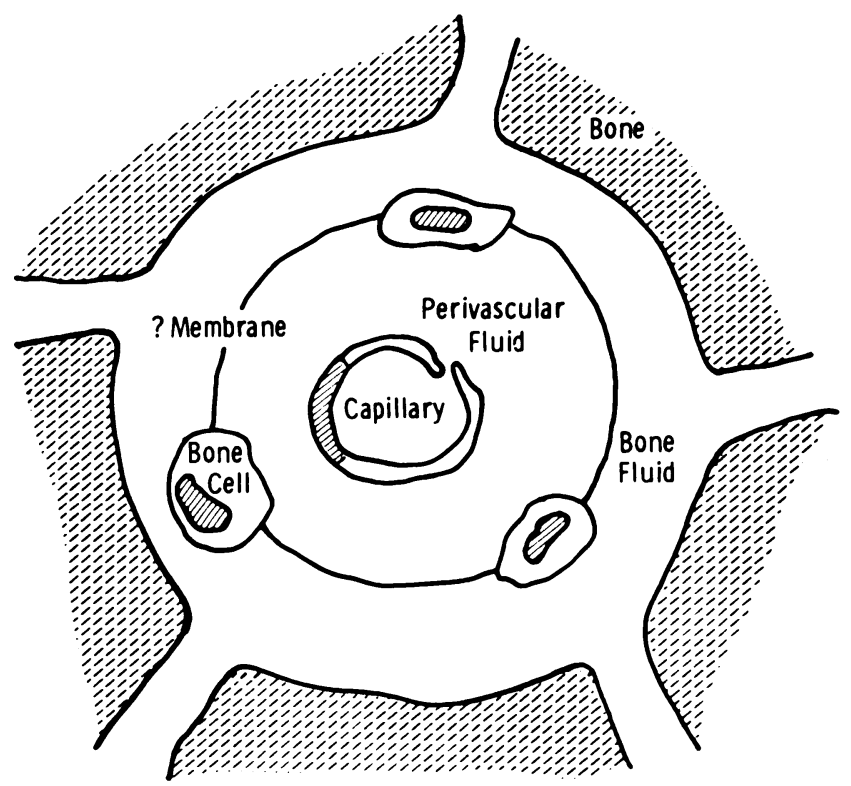

Fig. 3

A concept of the haversian system in bone to show the capillary separated from the bone cells by a fluid space. The bone cells may be linked by a membrane separating them from the bone crystal. 
space, the bone fluid space and the bone itself (Fig. 3). Therefore it appears that bone has a definite fluid space, allowing solutes to leave the capillaries by the process of passive diffusion and to pass across this fluid space to reach the hydroxyapatite crystal. That the solutes actually reach the bone is shown in Figure 4 which is an

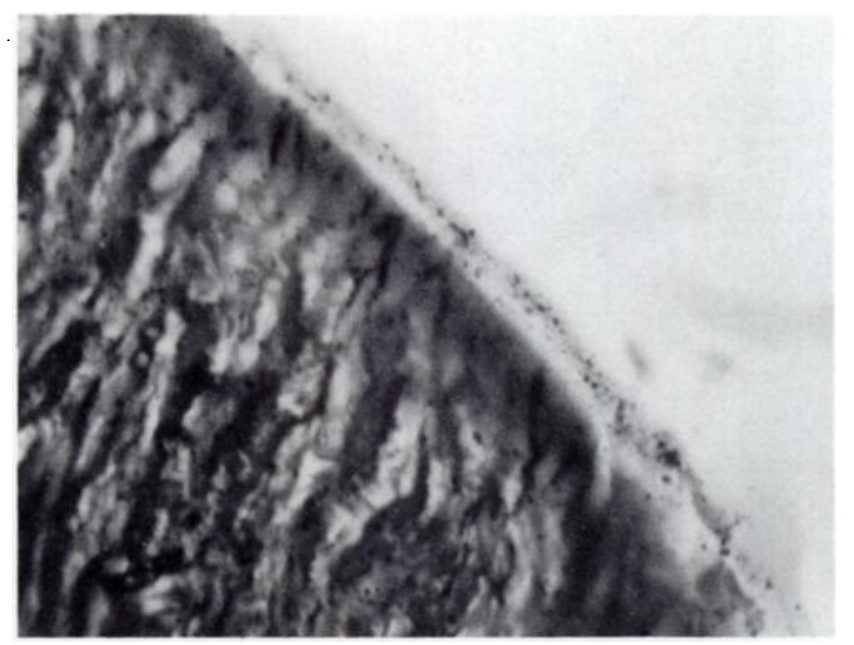

Fig. 4

An autoradiograph of a rat femur showing ${ }^{99 m} \mathrm{Tc}-\mathrm{MDP}$ in the bone and on the periosteal surface.

autoradiograph of a rat femur 10 hours after exposure showing the technetium-labelled diphosphonates distributed on both the bone structure and on the periosteal surface. This distribution is not uniform, and is related to both the vascular distribution and the nature of the bone matrix (Khan et al. 1979).

The effect of change in flow on extraction. Most pathological conditions in the body are associated with a change in the blood supply to the lesion. For example Rhinelander (1968) has shown that after a fracture there is an increase in the blood supply to the fracture site.

Paradis and Kelly (1975) found that between 10 and 14 days after a fracture in the canine tibia the blood flow to the bone increased fourfold. Hughes et al. (1979) demonstrated that although blood flow increased, the maximal instantaneous extraction did not change. This suggests that there is either an increase in the permeability of the capillary, which seems unlikely, or an increase in surface area from capillary recruitment and enhancement, enlarging the vascular bed available for mineral exchange. In order to differentiate between the effect of an increase in blood flow and an increase in bone turnover, Lavender, Khan and Hughes (1979) constructed experiments in which blood flow was measured using ${ }^{85} \mathrm{Sr}$-labelled microspheres injected into the nutrient artery of the canine tibia along with ${ }^{99 m}$ Tc-MDP (technetium-labelled methylene diphosphonate). The blood flow was simultaneously estimated by injection of the short-lived gas krypton-81. Profiles were obtained over both normal and fractured bone in the canine tibia and these profiles showed that although there was an increase in blood flow after a fracture as estimated by the microspheres and the krypton, there was a much greater increase in the profile of ${ }^{99 \mathrm{~m}} \mathrm{Tc}-\mathrm{MDP}$ for the same period of time. The authors concluded that although blood flow to bone is one determinant of the distribution of bone-seeking radionuclides such as ${ }^{99 m}$ Tc-MDP, some other factors of increased clearance from the residue explain their localisation; increased bone turnover may be such a factor. Hence mineral uptake is not simply an effect of an increase in blood flow. In order to examine the effect of changes in flow on bone uptake we then examined the residue of ${ }^{99 m} \mathrm{Tc}$ MDP in bone after an osteotomy of the canine tibia and found that, after an increase in blood flow, the residue increased threefold. This was not related simply to the contact time of the radionuclide as the residue of ${ }^{99 m}$ Tc-MDP at four hours was the same for a bolus as for an infusion (Table I; Hughes, Khan, Davies and Lavender 1978).

Summary. At this point it is possible to suggest that the normal mechanism of uptake of solutes in cortical bone is by passive diffusion through the capillaries of the haversian system. These solutes pass through transcapillary clefts and then across a fluid space before they enter the bone where they will bind or directly exchange with the basic crystal in bone. When blood flow to the bone is increased, as for example after a fracture, it appears that maximal instantaneous extraction does not alter. This is

Table I. Percentage residue of ${ }^{99 m}$ Tc-MDP (mean \pm SEM)

\begin{tabular}{|l|c|c|}
\hline & $\begin{array}{c}\text { Number } \\
\text { of animals }\end{array}$ & $\begin{array}{c}\text { Residue at } \\
4 \text { hours }\end{array}$ \\
\hline Bolus injection into normal bone & 5 & $4.9 \pm 1.0$ \\
Infusion into normal bone & 5 & $4.8 \pm 1.5$ \\
Bone after osteotomy & 3 & $13.4 \pm 1.1$ \\
\hline
\end{tabular}

From Hughes, Khan, Davies and Lavender, J Bone Joint Surg [Br] 1978;60-B:579-82

because the surface area increases from capillary recruitment and dilatation, allowing for a larger area of mineral exchange. In pathological conditions, such as after a fracture, there appears to be a fourfold increase in diphosphonate uptake in the tissue, suggesting that flow is only one factor in determining localisation of the diphosphonate compound. If the flow increases and the surface area increases, from capillary recruitment, it means that these substances are able to get to bone in much larger amounts. This enhances their exchange over a wide area of crystal formation, giving an increased amount of radionuclide in the bone at the time of bone scanning. 


\section{CLINICAL ROLE}

Radionuclides can be used for diagnosis in both benign and malignant disease.

Secondary malignant disease. Bone scanning with radiopharmaceutical products has been used to detect the spread of tumours into bone. Metastases to bone from carcinoma of the breast (Charkes and Sklaroff 1964) and the prostate (Roy et al. 1971) have been demonstrated by bone scanning, before the metastases were apparent on radiographs. Galasko (1972) has studied the spread of metastases in carcinoma of the breast and found that in 50 patients with advanced has also been studied. Samuels (1968) demonstrated pulmonary metastases from osteosarcoma by using strontium-87m, before they were apparent on radiographs. Ghaed et al. (1974) then showed that scanning with technetium polyphosphate might demonstrate pulmonary metastases before they were visible on radiographs. The use of technetium diphosphonate as a scanning agent to detect metastases from osteosarcoma has been reported (Hughes, Benson, Ell and Britton 1977). Sixteen patients with osteosarcoma were studied over a 12-month period comparing the techniques of bone scanning and radiography. It was possible to

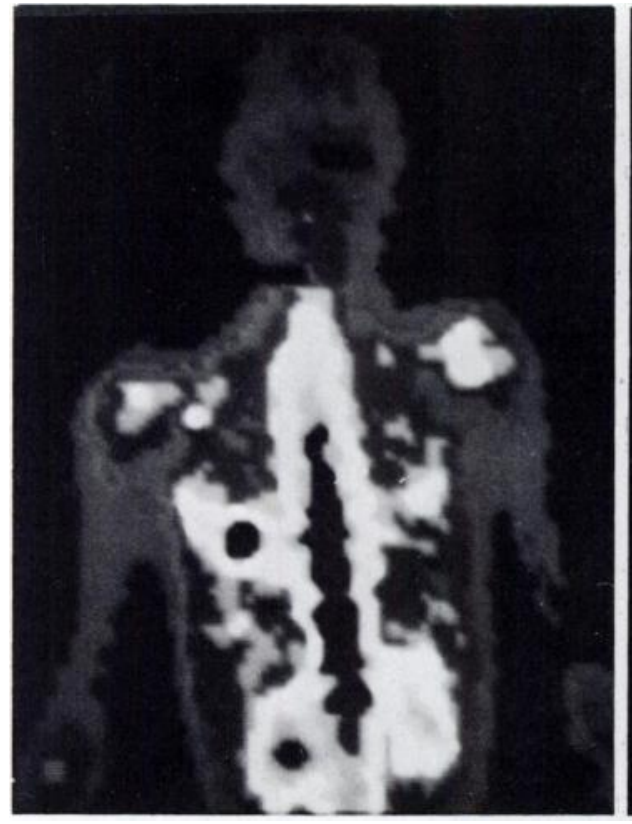

Fig. 5

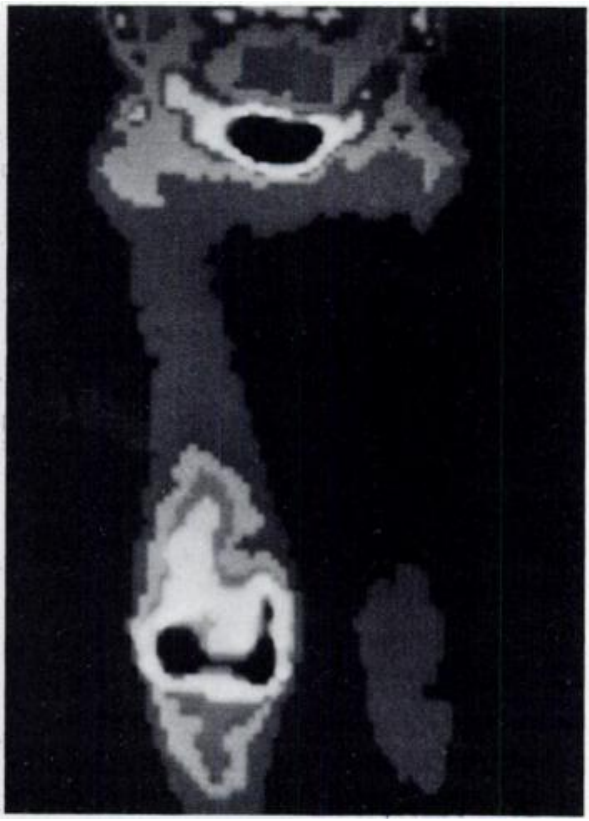

Fig. 6

Figure 5-A ${ }^{99 m}$ Tc-MDP bone scan of a 12-year-old girl with proven metastases in her lung. Figure $6-A^{99 m}$ Tc-MDP bone scan of a 14-year-old boy with an osteosarcoma of the lowermost third of the right femur showing uptake of the radionuclide.

disease, that is with some form of spread of the tumour, radiographs were positive in only 50 per cent, but a fluorine- 18 bone scan was positive in 84 per cent. In 50 patients with early cancer, that is without any detectable metastases, 12 patients had positive bone scans which were later confirmed to be due to metastases. In this situation bone scanning is invaluable in order accurately to stage the disease and to prevent extensive operations. In carcinoma of the bronchus, 30 per cent of 114 patients with early disease had positive scans (Shirazi $e t$ al. 1973), an incidence which rose to 50 per cent in later stages of the malignancy. Patients with carcinoma of the prostate have also been shown to benefit from the use of technetium diphosphonate in detecting lesions in the bone and assessing the response of skeletal metastases to treatment (Shearer et al. 1974).

Primary malignant diseases. The role of phosphate compounds in bone scanning in primary malignancies demonstrate metastases in the lung (Fig. 5) in four patients although in only two were the authors able to demonstrate the changes suggestive of pulmonary metastases any earlier with technetium diphosphonate than with a radiograph. In one of these patients the lesion resolved spontaneously and was therefore suggestive of a false positive. However, the bone scan did accurately delineate the extent of the primary tumour (Fig. 6) and may therefore be useful in deciding the level of amputation and the response of the patient to treatment, particularly now that chemotherapy (Jaffe et al. 1974) and immunotherapy (Neff and Enneking 1975) are being used in the management of this disease.

\section{Non-malignant conditions}

Infection. Infection after joint replacement is often not easy to diagnose until the changes are well established. Radiographs (Fig. 7) show both the periosteal reaction 


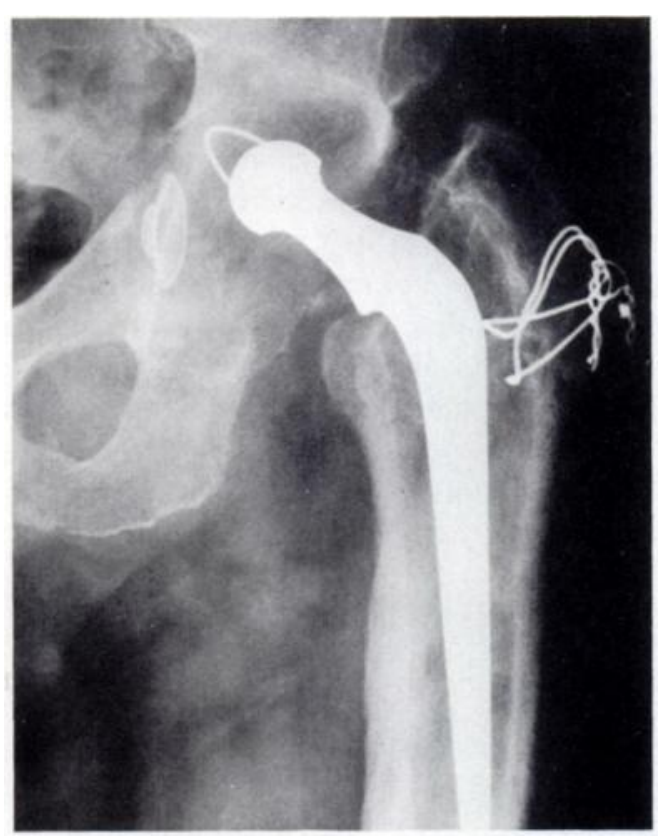

Fig. 7

A radiograph of a patient with an infected total hip prosthesis showing periosteal reaction and bone resorption in the femur.

and the bone destruction that are characteristic of established infection. However, I have had experience with the use of technetium diphosphonate in diagnosing infection after joint replacement and the results are of interest. Figure 8 demonstrates a total knee replacement which was causing the patient pain and showed a massive uptake of ${ }^{99 \mathrm{~m}} \mathrm{Tc}$-MDP in the uppermost third of the tibia which corresponded to an active infection due to Staphylococcus aureus. The prosthesis was removed and a new long-stem prosthesis inserted with antibioticimpregnated cement. Bauer et al. (1973) showed a clear correlation between infection and strontium-85 uptake. Other isotopes used include gallium-67 which has produced encouraging results, particularly in detecting acute osteomyelitis (Deysine et al. 1975). At the Hammersmith Hospital, London, indium-labelled white cells have been used in an attempt to detect infection after joint replacement but the results have not been encouraging: in 10 patients who were studied it was not possible to detect infection any earlier than with radiographs which showed the severe destructive changes characteristic of infection (Boland, personal communication).

Kemp et al. (1973) clearly demonstrated that fluorine-18 was useful in detecting infections involving the spine. It has recently been shown that bone scanning can detect ankylosing spondylitis in patients who present with back pain but have normal radiographs (Chalmers et al. 1979).

It is probable that the role of bone scanning in diagnosing infection is to act as an adjunct to clinical examination, radiographic changes and haematological investigation.
Perthes' disease. Morley, Short and Dowsett (1978) have developed a method for quantifying the uptake of technetium-labelled phosphate compound in the femoral head. They establish a reference area on the femoral shaft and compare the mean uptake of this area with that of the femoral head on each side; the activity of the femoral head is then presented as an uptake ratio. These ratios are then compared with those of the uptake at fixed points on the femoral head, providing more clinical information than the radiographs, particularly in the early stages of the unilateral or bilateral disease of the femoral head. They concluded that a femoral osteotomy introduced for the treatment of Perthes' disease produced vascularity in the femoral head which in certain cases persisted for several years. It is well known that in Perthes' disease there is impairment to the blood supply of the femoral head, producing avascular necrosis. Bohr (1973) using fluorine-18 also demonstrated that revascularisation of the epiphysis of the femoral head had usually taken place by the time the radiographs showed condensation and he concluded that the bone scanning was very effective in assessing the progress of the disease. This was confirmed by Danigelis et al. (1975) using ${ }^{99 m} \mathrm{Tc}$-polyphosphate.

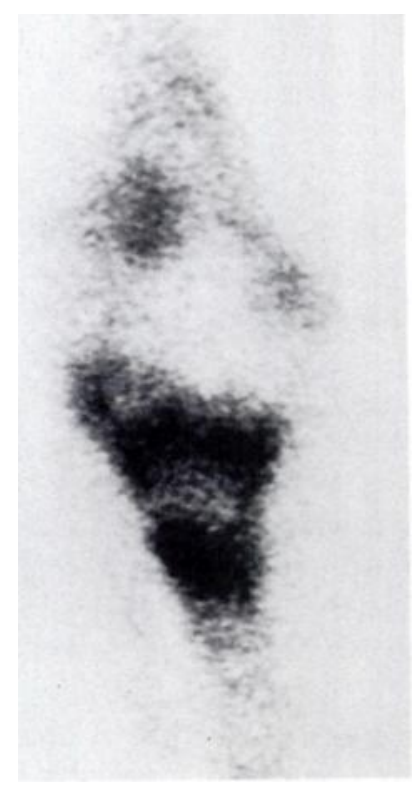

Fig. 8

A ${ }^{99 m} \mathrm{Tc}-\mathrm{MDP}$ bone scan of a patient with an infected left total knee prosthesis showing the area of absent uptake due to the prosthesis and increased uptake due to the infection in the bone.

Metabolic disease. Technetium diphosphonate and fluorine-18 have been used regularly for the assessment and management of patients with Paget's disease of bone (Miller et al. 1974).

Bony union. McMaster and Merrick (1980) have 
reported on the use of bone scanning with ${ }^{99 m} \mathrm{Tc}-\mathrm{MDP}$ in detecting the rate of bony fusion in 110 patients who had undergone spinal fusion for scoliosis. They concluded that pseudarthrosis could be demonstrated as a localised area of increased uptake on the bone scan performed six months after fusion.

Fractures. For a long time radionuclides have been used to assess the rate of healing of fractures, particularly subcapital fractures of the neck of the femur. Tucker (1950) introduced radioactive phosphorus in an attempt with fractures of the tibia and have developed a method of quantification based upon our experimental results. The ${ }^{99 m} \mathrm{Tc}-\mathrm{MDP}$ is injected systemically and profiles are obtained of the radionuclide on the fractured leg and the normal one. There is a pattern developing. Figure 9 shows a profile of a patient taken four weeks after the fracture of a tibia (Fig. 10); there is increased activity around the fracture site. On the other hand Figure 11 shows a profile of a patient who was developing delayed union because the plate was bending and the fracture not

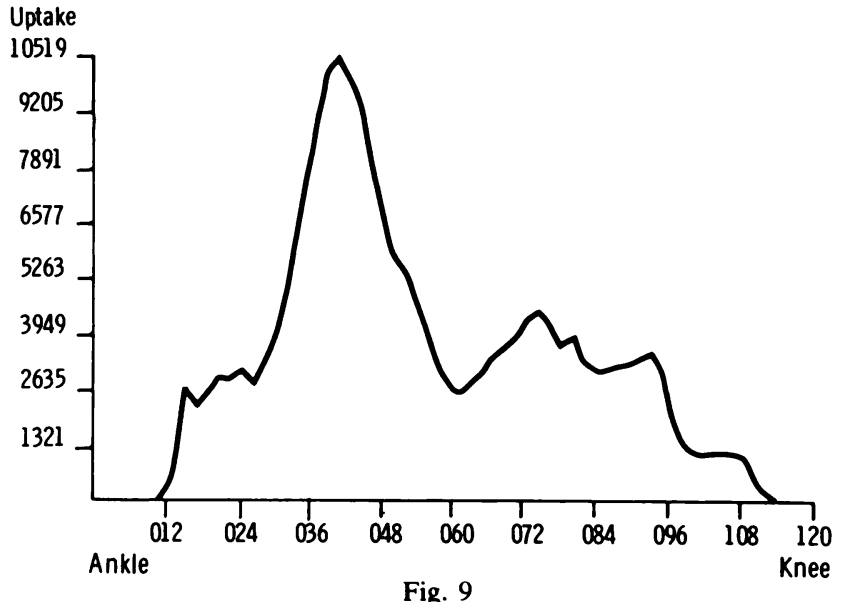

Fig. 9

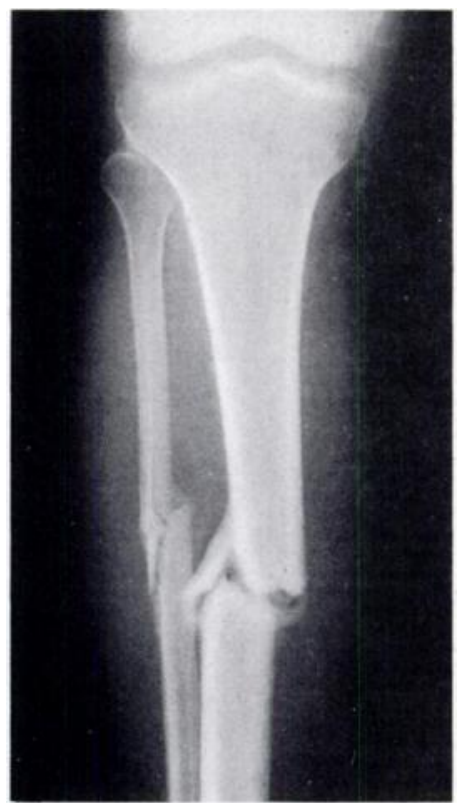

to give a prognosis for viability of the femoral head after subcapital fractures, but did not obtain clear results. Riggins et al. (1974) used fluorine-18 to detect vascularity after subcapital fractures in dogs: they found that a positive fluorine-18 scan was indicative of vascularity, while a negative scan indicated the absence of circulation to the femoral head.

Johannsen (1973) studied the ratio of uptake of strontium $-87 \mathrm{~m}$ in a fractured tibia compared with a normal tibia and noted an increase in activity over the fracture as union occurred. Illingworth and Schiess (1971) also reported on the role of strontium $-87 \mathrm{~m}$ in detecting union, comparing the fractured and nonfractured leg, but were unable to give a clear prediction of the rate of union from the bone scan taken within 24 hours of the injury. This would seem logical as at that stage there is a decrease in the blood supply to the bone, before the increase at 10 to 14 days which is associated with new bone formation as the fracture heals.

Muheim (1973) used serial bone scans to compare different methods of treating fractures and found that in a small group of patients, compression plating produced a fairly constant uptake of radionuclides over a period of 28 weeks.

Recently we have been studying healing in patients joining (Fig. 12); this showed increase in the uptake of radionuclides over the fracture site, four months after the fracture.

Obviously there is still a great deal of experimental and clinical work to be done on the role of bone scanning in fracture healing. However, the experimental and clinical results seem to be correlating and it may soon be possible to have a definite quantification of the uptake of radionuclide, which can be used to predict whether the fracture will go on to sound union or may proceed to non-union, because of a lack of adequate blood supply to the bone.

\section{CONCLUSIONS}

Bone scanning is a technique which is currently available for clinical use by orthopaedic surgeons. It offers the chance to look at bone in a dynamic role, to a much greater degree than does two-dimensional radiography.

Experimental work suggests that the bone scan reflects an increase in blood flow, which results in increase in surface area, which in turn results in a greater diffusion of radionuclides from the capillaries through the fluid spaces on to the hydroxyapatite crystal. It is therefore essential that there is a reasonable amount of viable hydroxyapatite available for uptake of the radionuclide. Galasko (1975) has suggested that it is the 
increased bone formation that accounts for the uptake of the isotope. It seems more probable, as he suggests later, that there is a two-phase mechanism in radionuclide uptake (Galasko 1977): a vascular phase and a bone phase. It is vital that there is an adequate amount of healthy bone available for exchange of the radionuclides, as simply sending an increased amount of the provision of mechanical support and the largest source of available calcium.

In practice, bone scanning is used routinely as a diagnostic screen for patients with malignant disease, particularly carcinoma of the breast. I believe that in orthopaedics, in the near future, bone scanning will be used to diagnose infection and to assess treatment,

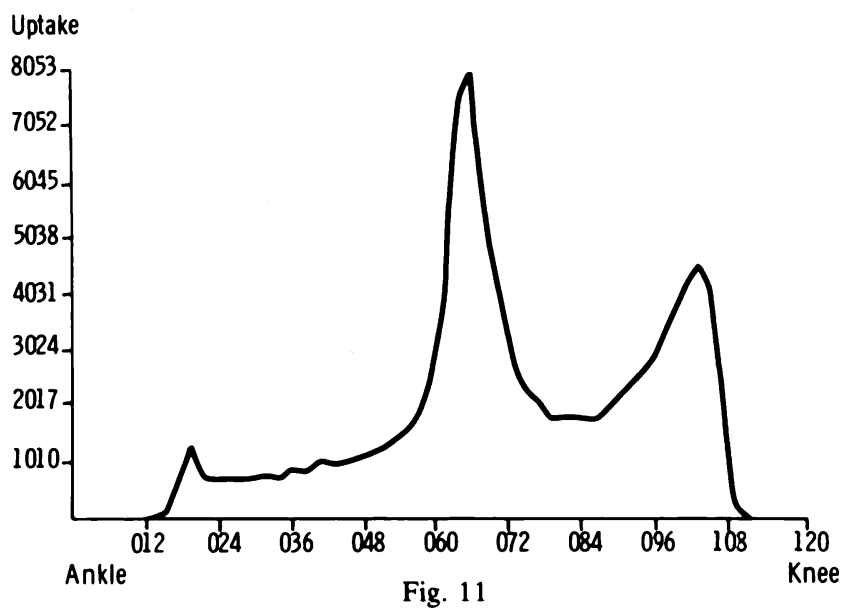

Fig. 12

Figure $11-$ The profile of a patient who had delayed union of the tibia,
showing a twin-peaked uptake which suggests increased activity at
both ends of the fracture. Figure $12-$ Radiograph showing the plate
bending and the fracture not uniting.

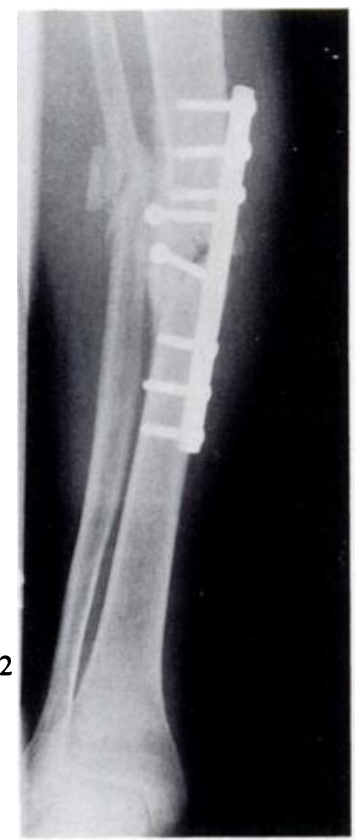

substance to the area, and not having the bone available, would not produce the increased uptake demonstrable on bone scans. Conversely, large areas of new bone, without an accompanying increase in vascular supply to bring the radionuclides to that area, could not show the increased uptake. There is evidence, however, that bone with increased metabolic turnover, such as in Paget's disease, takes up large amounts of diphosphonates. It is clear that in Paget's disease bone is both highly vascular and associated with plenty of immature bone. It is probable that investigations into the process of union will clarify the relative importance of these two phases.

In the future there may well be a diagnostic service in every district hospital which will be organised by doctors who have studied both nuclear medicine and radiology, so that a three-dimensional view of bone will be presented. Further advances are being made in the mechanism of mineral uptake in bone; other methods for measuring bone turnover include nuclear magnetic resonance and neutron activation analysis, both of which may soon be available for clinical use.

The future in this field is clearly very challenging and promises tremendous potential. Radionuclide uptake may demonstrate exactly what is taking place in bone and establish the vital roles of the skeleton: the particularly of Paget's disease, of osteosarcoma and of heterotrophic calcification. Possibly the most important use in orthopaedics will be in monitoring the union of a fracture: once a clear profile pattern is established, any fracture under clinical suspicion, where radiographic changes are equivocal, will be scanned and a prediction will then be possible whether or not the bone will go on to union. It should also be possible, once the uptake of radionuclide can be quantified, to use bone scanning to compare methods of treatment of fractures by measuring which technique gives a greater or lesser uptake of radionuclide.

We are entering into a new era of diagnostic medicine in which; working closely with our colleagues in the diagnostic department, we shall be able to assess treatment and to diagnose disorders. Possibly one of the most interesting prospects will be the ability to understand what is happening in bone and how it is affected by various factors such as changes in blood flow and bone turnover.

There is no doubt that a great deal of further work needs to be done on the uptake of minerals in bone, but this will be matched by the newer technology that is now available, in association with a knowledge of the biophysics of bone. 


\section{REFERENCES}

Bassingthwaighte JB. A concurrent flow model for extraction during transcapillary passage. Circ Res 1974;35:483-503.

Bauer GCH, Lindberg L, Naversten Y, Sjöstrand L-O. ${ }^{85} \mathrm{Sr}$ radionuclide scintimetry in infected total hip arthroplasty. Acta Orthop Scand $1973 ; 44: 439-50$.

Bohr H. Densitometry and 18-F scintigraphy in the study of the revascularization of the femoral head in coxa plana (C-P). Acta Orthop Scand 1973;44:417-25.

Branemark P-I. Experimental investigation of microcirculation in the bone marrow. Angiology 1961;12:293-305.

Brookes M, Harrison RG. The vascularization of the rabbit femur and tibiofibula. $J$ Anat 1957;91:61-72.

Brookes M, Elkin AC, Harrison RG, Heald CB. A new concept of capillary circulation in bone cortex. Lancet 1961;1:1078-81.

Chalmers IM, Lentle BC, Percy JS, Russell AS. Sacroiliitis detected by bone scintiscanning: a clinical, radiological, and scintigraphic follow-up study. Ann Rheum Dis 1979;38:112-7.

Charkes ND, Sklaroff DM. Early diagnosis of metastatic bone cancer by photoscanning with strontium-85. J Nucl Med 1964;5:168-179.

Citrin DL, Bessent RG, Tuohy JB, Elms ST, McGinlay E, Greig WR, Blumgart LH. Comparison of ${ }^{99 m}$ Tc-labelled polyphosphate, pyrophosphate and ethane hydroxydiphosphonate in patients with skeletal metastases (Abstract). Br J Surg 1974;61:330.

Clark WE LeG. Tissues of the body. 2nd ed. Oxford: Clarendon Press, 1945:104.

Cohen J, Harris WH. The three-dimensional anatomy of Haversian systems. J Bone Joint Surg [Am] 1958;40-A:419-34.

Cooper RR, Milgram JW, Robinson RA. Morphology of the osteon. J Bone Joint Surg [Am]1966;48-A:1239-71.

Crone C. Does "restricted diffusion" occur in muscle capillaries? Proc Soc Exp Biol Med 1963a;112:453-5.

Crone C. The permeability of capillaries in various organs as determined by the use of the "indicator diffusion" method. Acta Physiol Scand 1963b;58:292-305.

Danigelis JA, Fisher RL, Ozonoff MB, Sziklas JJ. ${ }^{90 m}$ Tc-polyphosphate bone imaging in Legg-Perthes disease. Radiology 1975;115:407-13.

Davies DR, Bassingthwaighte JB, Kelly PJ. Transcapillary exchange of strontium and sucrose in canine tibia. J Appl Physiol 1976;40:17-22.

Deysine M, Rankin H, Teicher IRA, Silver L, Robinson R, Manly J, Aufses AH Jr. Diagnosis of chronic and postoperative osteomyelitis with gallium 67 citrate scans. Am J Surg 1975;129:632-5.

Fick A. Ueber diffusion. Annals Physik 1855;94:59-86.

Galasko CSB. Skeletal metastases and mammary cancer. Ann R Coll Surg Engl 1972;50:3-28.

Galasko CSB. The pathological basis for skeletal scintigraphy. J Bone Joint Surg [Br] 1975;57-B:353-9.

Galasko CSB. The mechanism of uptake of bone seeking isotopes by skeletal metastases. In: International Atomic Energy Symposium on Medical Radionuclide Imaging, Los Angeles, 1976. Vienna: IAEA, 1977;2:125-236.

Ghaed N, Thrall JH, Pinsky SM, Johnson MC. Detection of extraosseous metastases from osteosarcoma with ${ }^{99 m}$ Tc-polyphosphate bone scanning. Radiology 1974;112:373-5.

Glimcher MJ, Andrikides A, Kossiva J. Studies of the mechanism of calcification. In: Jackson SF. Structure and function of connective and skeletal tissue. London: Butterworth 1965;234.

Hughes SPF, Jeyasingh K, Lavender PJ. Phosphate compounds in bone scanning. J Bone Joint Surg [Br] 1975;57-B:214-6.

Hughes SPF, Davies DR, Bassingthwaighte JB, Knox FG, Kelly PJ. Bone extraction and blood clearance of diphosphonate in the dog. Am J Physiol 1977;232:H341-7.

Hughes SPF, Davies R, Khan R, Kelly P. Fluid space in bone. Clin Orthop 1978;134:332-41.

Hughes SPF, Benson MKD, Ell PJ, Britton KE. The use of ${ }^{99 m}$ Tc-EHDP as a scanning agent in the detection of metastases from osteosarcoma. ROEFO 1977;126:551-5.

Hughes S, Khan R, Davies R, Lavender P. The uptake by the canine tibia of the bone scanning agent ${ }^{99 m}$ Tc-MDP before and after an osteotomy. $J$ Bone Joint Surg [Br] 1978;60-B:579-82.

Hughes SPF, Lemon GJ, Davies DR, Bassingthwaighte JB, Kelly PJ. Extraction of minerals after experimental fractures of the tibia in dogs. $J$ Bone Joint Surg $[$ Am $]$ 1979;61-A:857-66.

Illingworth GI, Schiess FA. Strontium 87m in the prognosis of fractures of the tibia. Proc $R$ Soc Med 1971;64:633-4.

Jaffe N, Frei E, Traggis D, Bishop Y. Adjuvant methotrexate and citrovorum-factor treatment of osteogenic sarcoma. $N$ Engl $J$ Med 1974;291:994-7.

Johannsen A. Fracture healing controlled by ${ }^{87 \mathrm{~m}} \mathrm{Sr}$ uptake. Acta Orthop Scand 1973;44:628-39.

Jung A, Bisaz S, Fleisch H. The binding of pyrophosphate and two diphosphonates by hydroxyapatite crystals. Calcif Tissue Res 1973;11:269-80.

Karnovsky MJ. The ultrastructural basis of transcapillary exchanges. J Gen Physiol 1968;52 Suppl:64S-93S.

Kemp HBS, Johns DL, McAlister J, Godlee JN. The role of fluorine-18 and strontium-87m scintigraphy in the management of infective spondylitis. J Bone Joint Surg [Br] 1973;55-B:301-11.

Khan RA, Hughes S, Lavender P, Leon M, Spyrou N. Autoradiography of technetium-labelled diphosphonate in rat bone.J Bone Joint Surg [Br] 1979;61-B:221-4.

Lavender JP, Khan RAA, Hughes SPF. Blood flow and tracer uptake in normal and abnormal canine bone. J Nucl Med 1979;20:413-8.

Lopez-Curto JA, Hughes SPF, Kelly PJ, Bassingthwaighte JB. Interstitial fluid space in bone (Abstract). Fed Proc 1976;35:850.

Lopez-Curto JA, Bassingthwaighte JB, Kelly PJ. Microvascular relationships of cortex and marrow of the canine tibia. Orthop Res Soc 1977:152.

Majno G. Ultrastructure of the vascular membrane. In: American Physiological Society. Handbook of Physiology Section 2, Circulation vol III. Washington DC: American Physiological Society, 1965; 2293-375.

McMaster MJ, Merrick MV. The scintigraphic assessment of the scoliotic spine after fusion. J Bone Joint Surg [Br] 1980;62-B:65-72.

Miller SW, Castronovo FP, Pendergrass HP, Potsaid MS. Technetium ${ }^{99 m}$ labeled diphosphonate bone scanning in Paget's disease. AJR 1974;121:177-83.

Morley TR, Short MD, Dowsett DJ. Femoral head activity in Perthes' disease: clinical evaluation of a quantitative technique for estimating tracer uptake. J Nucl Med 1978;19:884-90.

Muheim G. Assessment of fracture healing in man by serial ${ }^{87 m}$ Strontium-scintimetry. Acta Orthop Scand 1973;44:621-7.

Neff JR, Enneking WF. Adoptive immunotherapy in primary osteosarcoma. J Bone Joint Surg [Am] 1975;57-A:145-8.

Owen M, Trifitt JT, Melick RA. Albumin in bone. In: Elliott KM, Fitzsimons DW, eds. Hard tissue growth, repair and remineralization. Ciba Foundation Symposium. New series 11. Amsterdam: Elsevier, 1973;263-87.

Pappenheimer JR. Passage of molecules through capillary walls. Physiol Rev 1953;33:387-423.

Paradis GR, Kelly PJ. Blood flow and mineral deposition in canine tibial fractures. J Bone Joint Surg [Am] 1975;57-A:220-6.

Renkin EM. Transport of potassium-42 from blood to tissue in isolated mammalian skeletal muscle. Am J Physiol 1959;197:1205-10.

Rhinelander FW. The normal microcirculation of diaphyseal cortex and its response to fracture.J Bone Joint Surg [Am] 1968;50-A:784-800. 
Riggins RS, DeNardo GL, D'Ambrosia R, Goldman M. Assessment of circulation in femoral head by $18 \mathrm{~F}$ scintigraphy. $J$ Nucl Med 1974;15:183-6.

Robinson RA. An electron-microscopic study of the crystalline inorganic component of bone and its relationship to the organic matrix.J Bone Joint Surg $[\mathrm{Am}]$ 1952;34-A:389-434.

Roy RR, Nathan BE, Beales JSM, Chisholm GD. 18 Fluorine total body scans in patients with carcinoma of the prostate. Br J Urol $1971 ; 43: 58-64$.

Samuels LD. Lung scanning with Sr 87m in metastatic osteosarcoma. Am J Roent 1968;104:766-9.

Shearer RJ, Constable AR, Girling M, Hendry WF and Fergusson JD. Radioisotopic bone scintigraphy with the gamma camera in the investigation of prostatic cancer. Br Med J 1974;il: 362-5.

Shirazi PH, Stern AJ, Sidell MS, Rayudu GVS, Fordham EW. Bone scanning in the staging and management of brochogenic carcinoma: review. of 206 cases. J Nucl Med 1973;14:451.

Subramanian G, McAfee JG, O'Mara RE, Rosenstreich M, Mehter A. ${ }^{99 m}$ Tc polyphosphate PP46: a new radiopharmaceutical for skeletal imaging. J Nucl Med 1971;12:399-400.

Tucker FR. The use of radioactive phosphorus in the diagnosis of avascular necrosis of the femoral head. J Bone Joint Surg [Br] 1950;32-B:100-7.

Yano Y, McRae J, Van Dyke DC, Anger HO. Technetium-99m-labeled stannous ethane-1-hydroxy-1,1-diphosphonate: a new bone scanning agent. J Nucl Med 1973;14:73-8. 